\title{
1515 材料特性分布を有する固体面間に働くファンデルワールスカの理論解析
}

Theoretical analyses of the van der Waals forces acting between solid surfaces

with distribution of material properties

○学山本 健 (鳥取大·院) 正松岡 広成 (鳥取大·工) 正福井 茂寿 (鳥取大·工)

Takeru YAMAMAOTO, Tottori University, 4-101, Minami, Koyama, Tottori, 680-8552

Hiroshige MATSUOKA, ibid.

Shigehisa FUKUI, ibid.

1.はじめに

Key Words : Micro/nanotribology, Head-disk interface, van der Waals, DTM, BPM

磁気ディスク装置(HDD)の高記録密度化の一手段として、 データトラックを記憶するトラックの幅を狭める方法があ る。近年、データトラックを磁気的に分離するための溝 (グ ルーブ) を形成する DTM (Discrete Track Media: 離散トラッ クメディア)やBPM(Bit Patterned Media)が将来形態として考 案され、スライダの浮上特性等の研究が進められている。

本報告では、材料特性分布を有する表面間に働くファンデル ワールス引力 ${ }^{(1,2)}(\mathrm{vdW})$ をフーリ工級数の形で求め、数值解析 によりその特性を調べた。

\section{2. 解析手法}

本研究では、Fig. 1 のような系を考え、材料特性分布の繰 り返し性を有する表面と、材料が一様な表面との相互作用を 考えた。ここで、表面間距離を $D$, 材料分布の周期を $2 L$, 考え る面積要素の各辺の長さを $l, \beta$ とした。次に、 $\mathrm{vdW}$ 力の一般 式の導出過程について、2つの原子が距離 $r$ で相互作用すると きの原子間ポテンシャル $w(r)$ は、

$$
w(r)=-\frac{C_{\mathrm{m}}}{r^{N}}
$$

と表され、ファンデルワールスポテンシャル $(N=6)$ を考えた 場合の原子と表面との相互作用エネルギー $w\left(x_{0}, D\right)$ は、

$$
w\left(x_{0}, D\right)=-\int_{D-\infty}^{\infty} \int_{-\infty}^{\infty} \frac{C_{\mathrm{m}} \rho_{\mathrm{m}}}{r^{6}} d x d y d z
$$

ここで、原子間相互作用ポテンシャルにおける定数 $C_{\mathrm{m}}$ と材 料の分子数密度 $\rho_{\mathrm{m}}$ との積を、材料特性関数 $\sigma(x)$ と表す。さ らに、材料特性分布を有する表面の $x$ 方向のずれを $x_{0}$ とした。 これらをふまえ、 $\sigma(x)$ をフーリ工級数展開した場合、以下の 式(3)のように表される(Fig. 2)。

$$
\begin{aligned}
C_{\mathrm{m}} \rho_{\mathrm{m}} & =\sigma\left(x-x_{0}\right) \\
& =\frac{a_{0}}{2}+\sum_{n=1}^{\infty}\left\{a_{n} \cos \frac{n \pi\left(x-x_{0}\right)}{L}+b_{n} \sin \frac{n \pi\left(x-x_{0}\right)}{L}\right\}
\end{aligned}
$$

式(3) を用いて $w\left(x_{0}, D\right)$ を求めると

$$
\begin{aligned}
& w\left(x_{0}, D\right)=-\frac{a_{0} \pi}{12 D^{3}}-\sum_{n=1}^{\infty}\left[\left(a_{n} \cos \frac{n \pi x_{0}}{L}-b_{n} \sin \frac{n \pi x_{0}}{L}\right) \frac{\hat{p}_{n}(\hat{D})}{L^{3}}\right] \\
& \hat{p}_{n}(\hat{D})=\frac{3 \pi}{4} \int_{0}^{\infty}\left\{\cos (n \pi \hat{x}) \frac{2\left(\hat{x}^{2}+\hat{D}^{2}\right)^{3.2}-\hat{D}\left(3 \hat{x}^{2}+2 \hat{D}^{2}\right)}{3 \hat{x}^{4}\left(\hat{x}^{2}+\hat{D}^{2}\right)^{32}}\right\} d \hat{x}
\end{aligned}
$$

となる。また、無次元座標 $\hat{x}(=x / L)$, 無次元表面間距離 $\hat{D}(=D / L)$ である。式(5)の積分 $\hat{p}_{n}(\hat{D})$ については、数值積分を用いて求 めた。

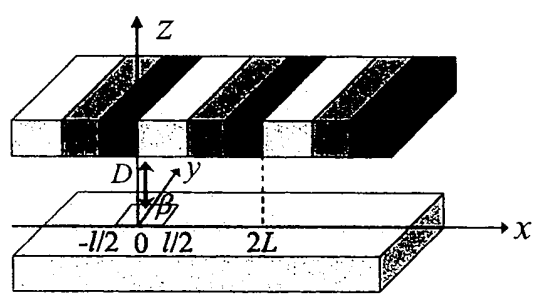

Fig. 1 Model of surfaces
次に、表面と表面のポテンシャルエネルギー $\Delta W$ は、 $\Delta W=w\left(x_{0}-x, D-z\right) \rho_{\mathrm{ms}} d x d y d z$ と表される。ここで、材料が一様な表面における分子数密度を $\rho_{\mathrm{ms}}$ とした。この式を積分することで表面間相互作用エネル ギーW $\left(x_{0}, D\right)$ は以下のように求められる。

$$
W\left(x_{0}, D\right)=\int_{-\infty}^{0} \int_{0}^{\beta} \int_{-2}^{12} w\left(x_{0}-x, D-z\right) \rho_{\mathrm{ms}} d x d y d z
$$
さらに、式(7)を表面間距離 $D$ で微分することで、材料特性 分布を有する表面間に働く $\mathrm{vdW}$ 力の一般式 $F\left(x_{0}, D\right)$ は、以下 のように求まる。以下の式については、 $y$ 方向単位長さ当り のvdW力として表記した。

$$
\begin{aligned}
& F\left(x_{0}, D\right)=-\frac{1}{\beta} \frac{\partial W\left(x_{0}, D\right)}{\partial D}=F_{0}(D)+F_{d}\left(x_{0}, D\right) \\
& F_{0}(D)=-\frac{a_{0} \pi \rho_{\mathrm{ms}} l}{12 D^{3}}
\end{aligned}
$$

$F_{d}\left(x_{0}, D\right)=-\frac{2 \rho_{\mathrm{ms}}}{\pi L^{2}} \sum_{n=1}^{\infty}\left[\frac{1}{n}\left(a_{n} \cos \frac{n \pi x_{0}}{L}-b_{n} \sin \frac{n \pi x_{0}}{L}\right) \cdot \sin \frac{n \pi l}{2 L} \cdot \hat{p}_{n}(\hat{D})\right]$

ここで、 $F_{d}\left(x_{0}, D\right)$ は、材料特性分布による $\mathrm{vdW}$ 力の変動を表 す項である。

\section{2種類の材料が交互に並んだ場合の解析例}

具体的な材料特性分布として、2種類の材料が交互に並ん でいる表面間を対象に解析を行った。まず、2種類の材料の 分布比を $\alpha:(1-\alpha)$ とすると (Fig. 2)、フーリ工係数はそれぞれ 以下のように表される。

$$
a_{0}=2 C_{1} \rho_{\text {md1 }} \alpha+2 C_{2} \rho_{\text {md } 2}(1-\alpha)
$$

$a_{n}=\frac{1}{n \pi}\left(C_{1} \rho_{\mathrm{md1}}-C_{2} \rho_{\mathrm{md2}}\right)\left\{(\cos 2 n \pi \alpha-1) \cdot \sin \frac{n \pi x_{0}}{L}+\sin 2 n \pi \alpha \cdot \cos \frac{n \pi x_{0}}{L}\right\}$

$b_{n}=-\frac{1}{n \pi}\left(C_{1} \rho_{\mathrm{md1}}-C_{2} \rho_{\mathrm{md} 2}\right)\left\{(\cos 2 n \pi \alpha-1) \cdot \cos \frac{n \pi x_{0}}{L}-\sin 2 n \pi \alpha \cdot \sin \frac{n \pi x_{0}}{L}\right\}$

次に、求めたフーリ工係数、式(11)〜(13)を式(8)に代入して 整理すると、以下のように表せる。

$$
\begin{aligned}
& F\left(x_{0}, D, \alpha\right)=F_{0}(D, \alpha)+F_{d}\left(x_{0}, D, \alpha\right) \\
& F_{0}(D, \alpha)=-\frac{A_{131} \alpha+A_{132}(1-\alpha)}{6 \pi D^{3}} l \\
& F_{d}\left(x_{t}, D, \alpha\right)=-\frac{2 \beta\left(A_{131}-A_{132}\right)}{\pi^{4} L^{2}} \sum_{n=1}^{x}\left[\frac{K_{n}}{n^{2}} \cdot \hat{p}_{n}(\hat{D})\right]
\end{aligned}
$$

Fig. 2 Distribution of material properties

日本機械学会講演論文集 No.115-1（'11-3，中国四国支部 第49期総会・講演会） 


$$
\begin{aligned}
& K_{n}=\left\{(\cos 2 n \pi \alpha-1) \cdot \sin \frac{n \pi x_{0}}{L}+\sin 2 n \pi \alpha \cdot \cos ^{2} \frac{n \pi x_{0}}{L}\right\} \cdot \sin \frac{n \pi l}{2 L} \\
& A_{131}=\pi^{2} C_{1} \rho_{\mathrm{md} 1} \rho_{\mathrm{ms}} \\
& A_{132}=\pi^{2} C_{2} \rho_{\mathrm{md} 2} \rho_{\mathrm{ms}}
\end{aligned}
$$

ここで、材料の組み合わせによって決まる定数 $C_{\mathrm{m}}$ と材料の 分子数密度 $\rho_{\mathrm{m}}$ をHamaker定数に結びつけ、それぞれの材料に よって決まる Hamaker 定数を $A_{131}, A_{132}$ とした。Hamaker 定数 とは、材料の屈折率によってきまる定数である。Fig. 3に、材 料 (屈折率)の組み合わせにおける Hamaker 定数の対応を示 す。ここで、屈折率 $n_{1}, n_{2}, n_{3}$ について、以下の值を用いた。
$n_{1}=1.9$
( 材料:DLC)
$n_{2}=k \cdot n_{1}$ ( $n$, の定数倍、 $k$ は定数)
$n_{3}=1.0$ (材料:空気)

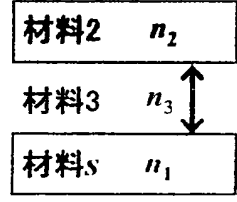

$A_{132}$

Fig. 3 Refractive index

なお、式(13)において、 $\alpha=0, \alpha=1$ の場合、材料がー一様な表 面間に㗢く通常のvdW力を表す式に帰着される。

$L=10 \mathrm{~nm}, l=10 \mathrm{~nm}, \alpha=0.5, k=1.1$ とした場合の、 $\mathrm{vdW}$ 力 $F\left(x_{0}\right.$, $D, \alpha)$ 、材料特性分布による $\mathrm{vdW}$ 力の変動成分 $F_{d}\left(x_{0}, D, \alpha\right)$ 、 材料特性分布の寄与による正味の $\mathrm{vdW}$ 力の変化率 $F_{d}\left(x_{0}, D, \alpha\right)$ $F\left(x_{0}, D, \alpha\right)$ をFigs. 4(a)〜 (c) に示す。Figs. 4(a), (b)より、正味の
$\mathrm{vdW}$ 力 $F\left(x_{0}, D, \alpha\right)$ は、 $\left.x\right) j$ 向のずれ量 $x_{0}$ に対して周期的に変 化し、無次元表面間距離 $\hat{D}$ が小さいほど変動幅は大きいことが 分かる。Fig. 4(c)より、材料特性分们による vdW 力の変化率 $F_{d}\left(x_{0}, D, \alpha\right) / F\left(x_{0}, D, \alpha\right)$ は、およそ $-20 \%$ 〜 $+10 \%$ ありり、無次 元表面間距離 $\hat{D}$ が小さいほど、変化率は大きい。

材料分布比 $\alpha=0.49, \alpha=0.51$ の場合の $F_{d}\left(x_{0}, D, \alpha\right)$ を Figs. 5, 6にそ れぞれ示す。ここで、 $A_{131}=1.81 \times 10^{-19} \mathrm{~J}, A_{132}=2.08 \times 10^{-19} \mathrm{~J}$ である。 2 種類の材料の分布比 $\alpha$ の值によって、 $\mathrm{vdW}$ 力の変動を表す 項 $F_{d}\left(x_{0}, D, \alpha\right)$ の最大值、最小值が変化する。

Fig. 7 に、 $\alpha=0.5, k=1.5$ とした場合の $F_{d}\left(x_{0}, D, \alpha\right)$ を示す。 ここで、 $A_{131}=1.81 \times 10^{-19} \mathrm{~J}, A_{132}=2.91 \times 10^{-19} \mathrm{~J}$ である。Fig. 4(b)の 場合より、変動幅が大きくなっていることが分かる。

\section{4. まとめ}

材料特性分布の繰り返し性を有する表面間に働く $\mathrm{vdW}$ を汎用的に解析する手法を確立した。特に、2種類の材料が 交互に並んでいる表面間を対象に、無次元表面間距離、材料 分布のずれ量、Hamaker定数が及ぼす影響を解析した。

材料分布のずれ量 $x_{0}$ に伴い、 $\mathrm{vdW}$ 力は周期的に変動し、 無次元表面間距離 $\hat{D}$ が小さいほど、変動幅は大きい。

\section{参考文献}

(1) 松岡広成，福井茂寿，日本機械学会論文集 $C$ 編，第69巻， 686号， (2003)， pp. 286-293

(2) J. N. イスラエルアチヴィリ，分子間力と表面力，第2版, (1996)，朝倉書店

\section{謝辞}

本研究において、鳥取大学工学部、土井俊行講師のご協力 を頂いた。ここに記し、謝意を表す。

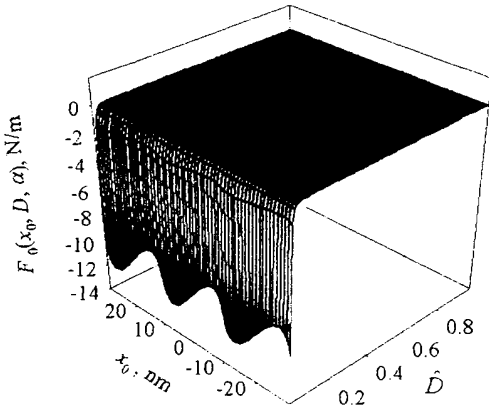

(a) $F\left(x_{n}, D, \alpha\right)$

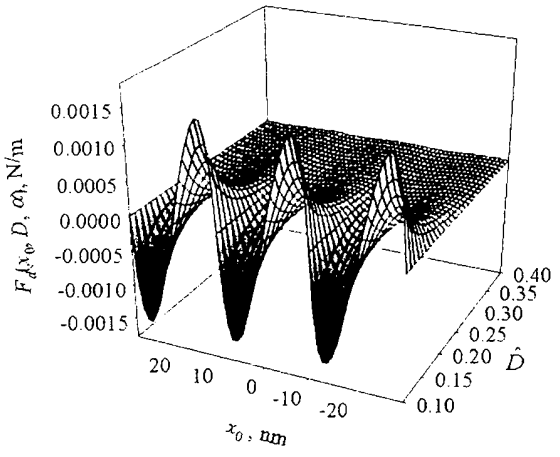

(b) $F_{d d}\left(x_{0}, D, \alpha\right)$

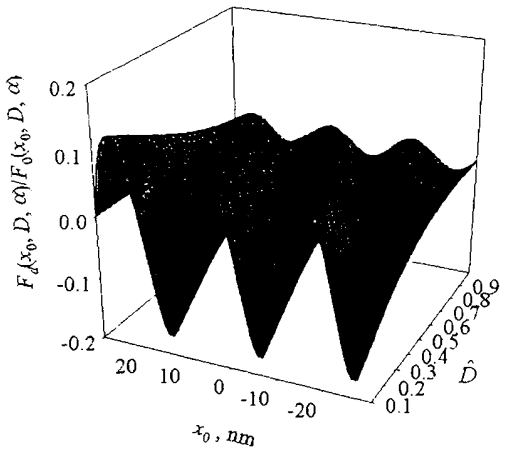

(c) $F_{d}\left(x_{0}, D, \alpha\right) / F\left(x_{0}, D, \alpha\right)$

Fig. $4 \mathrm{vdW}$ forces vs. $x_{0}$ and $\hat{D}$ for $\alpha=0.5, k=1.1, L=10 \mathrm{~nm}$

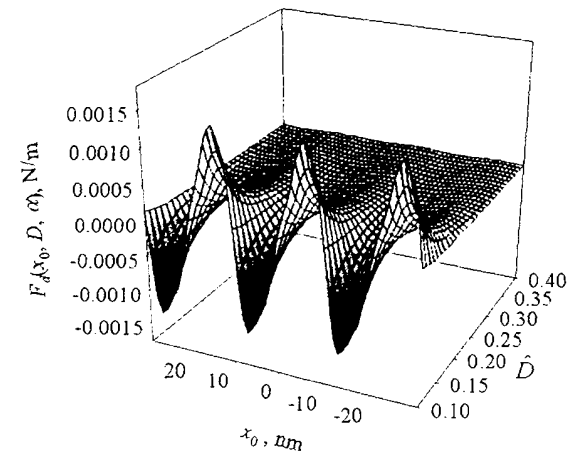

Fig. $5 F_{d}\left(x_{0}, D, \alpha\right)$ vs. $x_{0}$ and $\hat{D}$ for $\alpha=0.49, k=1.1, L=10 \mathrm{~nm}$

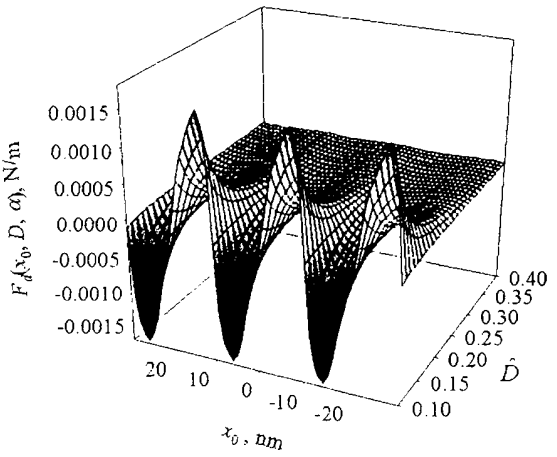

Fig. $6 F_{d}\left(x_{0}, D, \alpha\right)$ vs. $x_{0}$ and $\hat{D}$ for $\alpha=0.51, k=1.1, L=10 \mathrm{~nm}$

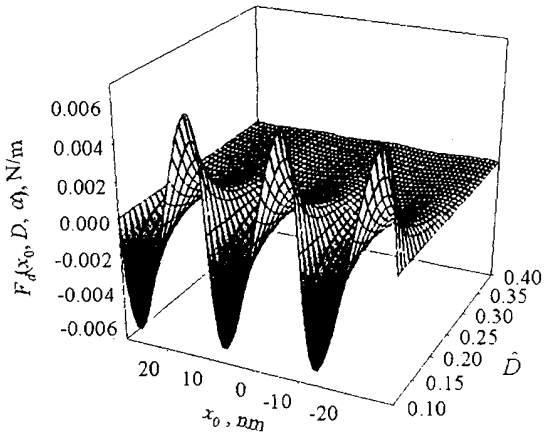

Fig. $7 F_{d}\left(x_{0}, D, \alpha\right)$ vs. $x_{0}$ and $\hat{D}$ for $\alpha=0.5, k=1.5, L=10 \mathrm{~nm}$ 